\title{
IDENTIFICAÇÃO E ANÁLISE DOS PONTOS CRÍTICOS DO CULTIVO DO MARACUJÁ NO ASSENTAMENTO VALE DO SOL II EM TANGARÁ DA SERRA- MT
}

\author{
Lenise Geraldo Ferrarini ${ }^{1}$ \\ Aparecida de Fátima Alves de Lima²
}

\section{RESUMO}

Neste trabalho buscou-se confrontar os custos de implantação e produção do maracujá informados pela indústria com os custos efetivamente ocorridos e levantados diretamente junto aos produtores rurais, a fim de verificar se realmente o plantio do maracujá representa uma opção rentável para os pequenos produtores Assentados. Os dados necessários para a análise dos custos foram coletados por meio de conversas informais com os produtores, entrevistas com o técnico responsável da Indústria processadora dos Frutos e manuseio nos documentos de despesas, como notas fiscais de compra relativos à implantação da lavoura, dos custos com manutenção, bem como, dos comprovantes de vendas da produção realizadas diretamente para a indústria. Os resultados desta pesquisa mostram que há uma divergência na estimativa de custos dos investimentos e da produção feita pela indústria com os custos efetivamente realizados pelos produtores, comprometendo deste modo a viabilidade do negócio e conseqüentemente, a saúde financeira das famílias assentadas. Vale ressaltar também, que foram percebidos durante o desenvolvimento da pesquisa, em alguns casos, que a falta de tradição na atividade rural, a baixa utilização de recursos tecnológicos, a falta de assistência técnica e a insuficiência de crédito contribuíram para o insucesso do plantio de maracujá no Assentamento.

Palavras-Chaves: Agricultura Familiar; Sustentabilidade; Maracujá; Viabilidade.

\section{INTRODUÇÃO}

Atualmente a Agricultura Familiar vem sendo bastante discutida como uma forma de renda já que segundo o Ministério do Desenvolvimento Agrário (MDA) este seguimento é responsável por $60 \%$ dos alimentos que chegam a mesa dos brasileiros, e pela matéria-prima para muitas indústrias representando $85 \%$ do total de estabelecimentos rurais no Brasil e é responsável por $10 \%$ do Produto Interno Bruto (PIB) nacional. No total, são aproximadamente 4,1 milhões de famílias agricultoras, pescadoras, extrativistas, ribeirinhas , integrantes de comunidades quilombolas e indígenas produzindo, gerando renda e responsável por $77 \%$ dos empregos no campo. Estes dados podem justificar o alto investimento do Governo Federal neste setor, já que o mesmo é de grande importância para o país, pois alem

\footnotetext{
${ }^{1}$ Acadêmica do curso de Ciências Contábeis da UNEMAT - Campus de Tangará da Serra, le.ferrarini@hotmail.com

${ }^{2}$ Mestre em Administração (UFRN), Professora do curso de Administração da UNEMAT - Campus de Tangará da Serra, afal.lima@gmail.com
} 
de produzir alimentos, gera emprego e renda no campo, e assim contribui para o Brasil construir e desenvolver um padrão de desenvolvimento sustentável.

Através do Programa Nacional de Crédito Fundiário e com a parceria entre Estado e Município foi criado em 2007 o Assentamento Vale do Sol II,com 191 lotes de 5 há cada, destinados a pequenos produtores rurais. Segundo dados do MDA, uma das justificativas para a implantação deste assentamento foi a possibilidade de geração de renda para as famílias Assentadas com a produção de frutas, pois Tangará da Serra-MT conta com uma indústria beneficiadora de poupa de frutas com capacidade para processar até 180 toneladas/dia, e tem por objetivo fomentar a produção de frutíferas como maracujá, abacaxi etc, nas pequenas propriedades rurais do município, porem a industria opera com excessiva ociosidade devido a escassez de matéria prima.

Com base nas informações apresentadas pela indústria a cultura do maracujá constituise em alternativa de produção econômica e financeiramente viável para os pequenos produtores rurais. Contudo, os produtores rurais Assentados que aderiram a essa opção de plantio tem encontrado dificuldades financeiras para a manutenção de suas famílias e para cumprir com os compromissos financeiros relativos ao financiamento da terra. Neste artigo serão confrontados dados fornecidos pela industria com os custos levantados diretamente nas propriedades rurais para verificar se realmente trata-se de uma opção rentável para os pequenos produtores Assentados. Assim buscou-se responder quais fatores interferiram diretamente na produção do maracujá e que comprometeram o desempenho dessa cultura no Assentamento Vale do Sol II?

A pesquisa tem como objetivo geral contribuir com a gestão de custos na agricultura familiar a partir da análise de custos na produção de maracujá no Assentamento Vale do Sol II.

E para alcançar este objetivo foram estabelecidos os seguintes objetivos específicos:

- Identificar os custos de produção;

- Analisar os aspectos de rentabilidade e lucratividade na cultura do maracujá.

Para o desenvolvimento da pesquisa foi utilizado como base o método cientifico de pesquisa quanto a forma de estudo descritiva. Quanto aos procedimentos, realizou-se um estudo de caso no Assentamento Vale do Sol II no município de Tangara da Serra-MT, e foi utilizado também o método de pesquisa bibliográfica, em livros, revistas, artigos, e o método de pesquisa documental, que se deu por meio de verificação e analise de documentos fiscais 
de posse do produtor rural. As informações sobre a indústria foram obtidas através de aplicação de questionário com o técnico responsável pela produção.

\title{
CONTABILIDADE DE CUSTOS
}

\subsubsection{HISTORIA DA GESTÃO DE CUSTOS}

De acordo com Martins (2001, p.21), até a Revolução Industrial praticamente só se usava a contabilidade financeira, o contador apurava o resultado com a contagem do estoque, tirava do total das compras esse valor e chegava-se então ao custo das mercadorias vendidas, tirava esse total da receita com as vendas e encontrava o lucro bruto.

Com o advento da Revolução Industrial sentiu-se a necessidade de uma informação mais completa, com isso surgiram os critérios de avaliação dos estoques.

\begin{abstract}
A preocupação primeira dos Contadores, Auditores e Fiscais foi a de fazer da Contabilidade de Custos uma forma de resolver seus problemas de mensuração monetária dos estoques e do resultado, não a de fazer dela um instrumento de administração. Por essa não utilização de todo seu potencial no campo gerencial, deixou a Contabilidade de Custos de ter uma evolução mais acentuada por um longo tempo. (MARTINS, 2001, p. 21).
\end{abstract}

Ainda de acordo com Martins, a preocupação era a avaliação dos estoques e não obter informação precisa para tomada de decisão.

Atualmente a contabilidade de custos é essencial em todos os ramos de atividades, pois é através dela que é possível ter informações para que o gestor possa melhorar seu resultado.

Conforme Megliorini, as informações geradas pela contabilidade de custo subsidiam:

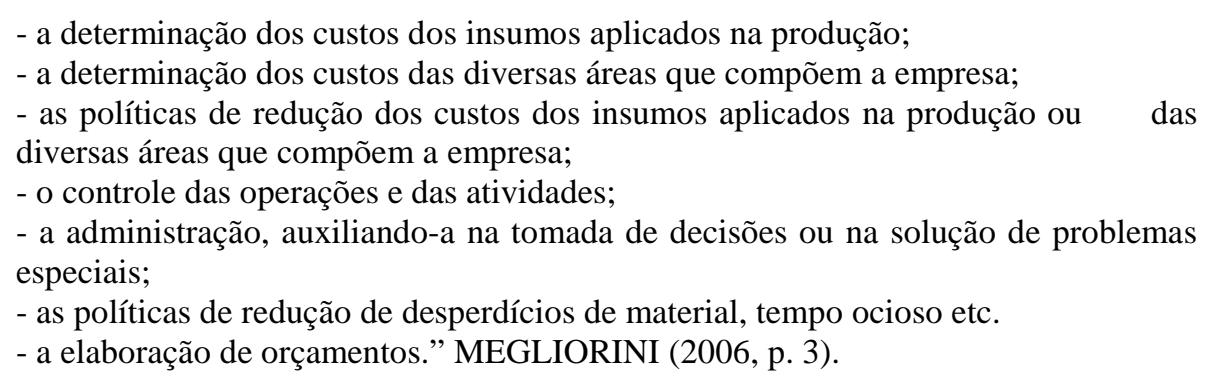

\subsection{TERMINOLOGIA DA GESTÃO E IMPLANTAÇÃO DE SISTEMAS DE CUSTO}

A área de custos tem uma terminologia própria e muitas vezes é utilizadas de forma equivocada. Assim sendo, é bom definir os termos utilizados para facilitar o entendimento:

“Gasto: Sacrifício financeiro com que a entidade arca para a obtenção de um produto ou serviço qualquer, sacrifício esse representado por entrega ou promessa de entrega de ativos (normalmente dinheiro)". (MARTINS, 2001, p. 25) 
Gastos correspondem aos compromissos financeiros assumidos por uma empresa no tocante à aquisição de:

- recursos que serão consumidos no ambiente fabril para a fabricação do produto;

- mercadorias para revenda;

- recursos para realização de serviços;

- recursos a ser consumidos no ambiente de administração;

- recursos a ser consumidos no ambiente comercial; (MEGLIORINI, 2006, p. 7)

Todo desembolso efetuado pela empresa em exercício de sua atividade é um gasto, independente de sua finalidade.

"Investimento: Gasto ativado em função de sua vida útil ou de benefícios atribuíveis a futuro(s) período(s)". (MARTINS, 2001, p. 25)

A aquisição de bens para o Ativo Permanente da empresa pode ser considerada como investimento, um exemplo na atividade rural é a construção de cerca.

“Custo: Gasto relativo à bem ou serviço consumidos na produção de outros bens ou serviços”. (PEREZ, OLIVEIRA E COSTA, 2008, p. 22)

O custo é um gasto diretamente ligado à produção, por exemplo: matéria prima, energia, mão de obra, etc.

"Despesa: Gastos relativos aos bens e serviços consumidos no processo de geração de receitas e manutenção dos negócios da empresa. (PEREZ, OLIVEIRA E COSTA, 2008, p. 22)

A despesa está intimamente ligada a uma receita, pois para que se tenha uma receita é necessário que se tenha um "sacrifício".

"Perda: Bem ou serviço consumidos de forma anormal e involuntária.

Perda é um gasto não previsível, e não está ligado à obtenção da receita, é algo que foge ao controle da empresa e diminui o seu resultado.

\subsection{SISTEMAS DE CUSTOS}

Os sistemas de custos surgiram a partir da necessidade de obter dados que fossem úteis para controle e tomada de decisão.

De acordo com Martins (2001, p. 28), nenhum sistema de custo é capaz de resolver todos os problemas da empresa, para que um sistema funcione é preciso que todos envolvidos no processo desempenhem suas funções com zelo a fim de alimentar o sistema com dados corretos, pois através destes que serão geradas as informações.

O sucesso de um sistema de informações depende do pessoal que o alimenta e o faz funcionar. $\mathrm{O}$ sistema representa um conduto que recolhe dados em diversos pontos, processa-os e emite, com base neles, relatórios na outra extremidade. Esses relatórios não podem ser, em hipótese alguma, de qualidade melhor do que a qualidade dos dados recebidos no inicio do processamento. Podem é ser pior, se seu manuseio não for absolutamente correto. Mas todos os dados iniciais quase sempre 
dependem de pessoas, e, se estas falharem ou não colaborarem, todo o sistema acabará por falir. (MARTINS, 2001, p. 21)

Implantação de um sistema de custos tem todo um processo, que envolve desde um ótimo planejamento à qualificação e empenho do pessoal envolvido.

\subsection{CLASSIFICAÇÃO DOS CUSTOS - ATIVIDADE RURAL}

$\mathrm{Na}$ contabilidade rural aprende-se a compreender o funcionamento da atividade rural, tanto pecuária quanto agrícola, estudando sua forma de contabilização e como controlar seus estoques, receitas, custos e despesas para servir de auxilio ao pequeno, médio ou grande produtor na administração e nas tomadas de decisões

\subsubsection{Custos diretos e indiretos}

De acordo com Megliorini (2006, p. 9), conclui-se que:

Custos diretos são apropriados aos produtos de acordo com sua produção, como matéria prima, mão de obra direta, sendo distribuídos diretamente ao produto.

Custos indiretos são atribuídos aos produtos com base em um rateio, como energia, utilização das máquinas.

Assim pode-se dizer que aqueles custos ligados diretamente a produção, que podem ser facilmente visualizados sem rateio, são considerados custos diretos e aquele que estão ligados a produção porem são necessários que sejam feitos cálculos mais detalhados, são considerados indiretos. Um exemplo de custo direto na produção são as mudas do maracujá e o indireto pode ser a energia elétrica gasta com a bomba para irrigação.

\subsubsection{Custos fixos e variáveis}

Conforme Perez, Oliveira e Costa (2008, p. 26) os custos são classificados também como fixos e variáveis de acordo com o comportamento dos custos em função da quantidade da produção.

Custos fixos são aqueles que independem da quantidade que possa ser fabricada, por exemplo, o valor pago pelo controle Fitossanitário.

Custos variáveis, como o próprio nome diz, variam de acordo com a quantidade da produção, como por exemplo os adubos gastos na plantação.

Através deste conceito pode-se exemplificar que em uma produção de maracujá um dos custos fixo se dá pelo valor retirado pelo produtor como sendo o seu salário pois este não depende do tanto que ele produziu ou colheu da fruta, o valor não será alterado sendo este fixo, e o custo variável seria a quantidade e o valor que este produto gasta de adubos, pois 
estes dependem da necessidade que a terra tem em relação ao tamanho da área ou a quantidade de pés da fruta que serão plantados.

\subsection{GESTÃO DE CUSTOS}

A Gestão de Custos é o fator mais relevante para qualquer sistema produtivo, pois baseado nos custos é que as decisões são tomadas, isso garante a sobrevivência no mercado. Quem não conhece os custos de produção pode estar comercializando seus produtos a um valor não condizente, ou seja, abaixo do valor de custo, fazendo com que tenha prejuízos ou acima do preço de mercado, gerando excedentes de produção sem comercialização.

\subsubsection{Custos para melhoria de processos e eliminação de desperdícios}

Para Perez, Oliveira e Costa (2008), além de conhecer e controlar os custos, é necessário identificar as possibilidades de melhorias de processos que resultem em identificação e eliminação de desperdícios que oneram o custo da produção e reduzem a lucratividade ou a competitividade no mercado.

\subsubsection{Custos para tomada de decisões}

Perez, Oliveira e Costa (2008, p. 193) "esse sistema fundamenta-se na separação dos gastos em variáveis e fixos, isto é, em gastos que oscilam proporcionalmente ao volume da produção e vendas e gastos que se mantém estáveis perante volumes de produção e vendas oscilantes dentro de certos limites".

Essa separação é essencial na apuração dos custos totais, pois assim é possível calcular exatamente o custo.

Perez, Oliveira e Costa (2008, p. 28)

O termo custos variáveis designa os custos que, em valor absoluto, são proporcionais ao volume da produção dentro de certos limites, isto é, oscilam na razão direta dos aumentos ou reduções das quantidades produzidas. O total dos custos variáveis oscila proporcionalmente ao volume da produção,entretanto, o custo variável por unidade mantém-se constante dentro do intervalo da análise.

\section{AGRICULTURA FAMILIAR}

A expressão "agricultura familiar" surgir na década de 90 no século $\mathrm{XX}$, com os movimentos dos sindicatos rurais enfrentando vários desafios como falta de credito e queda dos preços dos produtos agrícolas, em 1996 o Programa Nacional de Fortalecimento da 
Agricultura Familiar (PRONAF), surgiu com a finalidade de prover crédito agrícola e apoio aos pequenos produtores rurais, fortalecendo os sindicatos.

De acordo com Neuman (2009 p.22):

... não raramente uma parte dos membros das famílias residentes no meio rural passa a se dedicar a atividades não agrícolas, praticadas dentro ou fora das propriedades. Essa forma de organização do trabalho familiar vem sendo denominada pluriatividade e referem-se a situações sociais em que os indivíduos que compõem uma família com domicilio rural passam a se dedicar ao exercício de um conjunto variado de atividades econômicas e produtivas (...).

De acordo com o autor, é cada vez mais freqüente que os membros de famílias que ainda se encontram na zona rural, trabalham com atividades variadas, e isso não acontece somente em países de primeiro mundo.

Conforme Portugal (2004), no Brasil são cerca de 4,5 milhões de estabelecimentos, dos quais metade estão no nordeste e estes detêm $20 \%$ das terras e corresponde a $30 \%$ da produção global e até $60 \%$ na produção de alimentos básicos como arroz, feijão e etc.

Esta inserção no mercado ou no processo de desenvolvimento depende de tecnologia e condições político-institucionais, representadas por acesso a crédito, informações organizadas, canais de comercialização, transporte, energia, etc. Este último conjunto de fatores normalmente tem sido a principal limitante no desenvolvimento. (Portugal, 2004 p.29)

A tecnologia desenvolvida tem como o objetivo facilitar o trabalho dos produtores e também aumentar a produtividade da terra e o desafio dos agricultores é se adaptar a essa tecnologia.

Segundo a Embrapa a tecnologia tem tentado acompanhar e auxiliar no processo de transformação do produto agrícola e isso é muito importante para população brasileira, inclusive é uma das principais diretrizes do Plano Diretor da Embrapa que consiste em um planejamento estratégico onde são estabelecidas linhas de orientação para as atividades a serem desenvolvidas por ela.

\section{CULTURA DO MARACUJÁ}

O maracujá é uma planta nativa da América Tropical que é cultivada atualmente em diferentes partes do mundo. Ele tem mais de 150 espécies nativas no Brasil e, devido as suas propriedades terapêuticas, tem valor medicinal.

Segundo o Instituto Centro de Ensino tecnológico (CENTEC) na década de 70, a comercialização desse produto era apenas praticada no mercado in natura. Nos anos 80, as indústria extratoras de suco estimularam a expansão da cultura e o mercado do produto 
industrializado. $\mathrm{Na}$ década de 90 , a cultura apresenta sua maior expansão como uma alternativa agrícola para a pequena propriedade.

Ainda segundo o CENTEC o cultivo dessa fruta deve ser feito com muito cuidado pois os procedimentos são delicados e levam tempo e precisam de muita atenção. As primeiras colheitas levam de 8 a 9 meses após o plantio. Na colheita devem ser utilizadas caixas plásticas para os frutos ficarem na sombra para protegê-los da queimadura do sol. Apesar de todos esses cuidados, a cultura depende de fatores como clima, solo, espaçamento, tratos culturais e controle fitossanitário . No Brasil essa cultura é muito bem desenvolvida, destacando assim o País como sendo o primeiro produtor mundial de maracujá e um dos principais exportadores de seu suco ao lado da Colômbia e do Equador.

Segundo dados da Embrapa dentre os 18 gêneros desta fruta, o de maior importância econômica é o Passiflora que é formado por 24 subgêneros e 465 espécies, dentre essas espécies de 150 a 200 são originarias do Brasil. O maracujazeiro pode ser plantado por meio de sementes, estaquia e enxertia o mais usado no Brasil devido as condições aqui encontradas é a propagação através da semente por ser um método barato e de fácil execução.

Atualmente a fruticultura não é o forte do estado de Mato Grosso, segundo reportagem publicada no jornal Gazeta em 2010, já existem culturas consolidadas nos municípios de Tangará da Serra, Sinop, Terra Nova do Norte e Nova Mutum. O que garantiu o processamento da produção de frutas nessas cidades foi a chegada da agroindústria. Pelo fato do estado estar apoiado na produção de grãos, a implantação desta atividade no estado é lenta mas evoluiu muito nos últimos anos e pela capacidade de produção de Mato Grosso, este esta incentivando os pequenos produtores com cursos e parcerias com Municípios.

Segundo presidente da Sociedade Mato-grossense de Fruticultura, Duílio Maiolino, o cultivo de frutas é uma forma de diversificar as atividades da agricultura familiar, mas para isso segundo ele é preciso que os fruticultores se organizem para abastecer as indústrias já instaladas no estado, pois atualmente nenhuma destas instituições estão produzindo na sua capacidade máxima pela falta da matéria-prima.

Segundo o Engenheiro Agrônomo do Mt Legal, Antonimar Marinho, pelo menos $67 \%$ das frutas comercializadas em Mato Grosso são oriundas de outros estados, isso totaliza aproximadamente $\mathrm{R} \$ 300$ milhões por ano para adquirir estas frutas, e ele coloca ainda que se o estado produzir para abastecer o mercado interno o Imposto sobre Circulação de Mercadorias e Serviços (ICMS) sobre esse valor estará girando dentro do estado e terá varias 
outras vantagens. A participação do mercado mato-grossense na fruticultura brasileira não chega a $1 \%$.

\section{METODOLOGIA}

Para Both (2004) metodologia é o conjunto, de passos e itens para a elaboração do projeto. A metodologia de um projeto caminha e direção ao resultado, ou seja, explica como chegar a ele, passo-a-passo.

Para Bezzon (2005 p. 31):

Esta parte do projeto é da maior importância, pois, se não traçarmos um caminho para aplicação de nossa pesquisa, tudo o que fizemos ficará no papel, pois não saberemos como começar e colocar em prática tudo o que pretendemos no projeto e, neste caso, nosso problema nunca será respondido, nossas hipóteses continuarão hipóteses e nossos objetivos jamais serão alcançados.

O trabalho teve como base o método cientifico de pesquisa quanto a forma de estudo descritiva. Neste sentido descritivo o pesquisador estudou o caso, sem manipulação de nenhum resultado, assim, foi trabalhado somente com dados e documentação fornecidos pelo produtor.

Quanto aos procedimentos, foi realizado uma pesquisa Exploratória através de um estudo de caso no assentamento Vale do Sol II localizado em Tangara da Serra-MT, onde foram fornecidos pelos produtores informações através de conversas informais e notas fiscais relacionadas ao tema e entrevista através de aplicação de questionário com o técnico responsável pela Tropical Poupa de Frutas, o que possibilitou uma minuciosa apuração dos custos da produção do maracujá.

Quanto aos procedimentos, utilizou-se o método de pesquisa bibliográfica com a realização de pesquisas em livros, revistas, internet, entre outros, e o método de pesquisa documental através da analise de notas fiscais e documentos diretos do produtor.

\section{DISCUSSÃO DOS RESULTADOS}

A cidade de Tangará da Serra - MT é polo de produção do maracujá e abacaxi, segundo o pesquisador da Empresa Mato-grossense de Pesquisa, Assistência e Extensão Rural (Empaer), Hélio Kist, isso se deve ao fato da existência de uma indústria de poupa concentrada na região com capacidade de produzir 180 toneladas de poupa por dia. Para incentivar os pequenos produtores, foi criada uma parceria com a Prefeitura Municipal de Tangará da Serra - MT onde é plantado em seu viveiro mudas para que sejam distribuídas aos fruticultores sem custo algum. Desta forma foi criado em 2007 o Assentamento Vale do Sol 
II, no município de Tangará da Serra pelo Programa Nacional de Crédito Fundiário (PCNF). Ao todo foram atendidas 191 famílias de trabalhadores rurais que tiveram acesso a terra por meio da concessão de financiamentos tanto para a aquisição da terra, quanto para investimentos básicos destinados à estruturação das unidades produtivas, com custo financeiro de $2 \%$ ao ano e longo prazo para pagamento. Inicialmente, o projeto do Assentamento previa o plantio de frutas que seriam comercializadas diretamente para uma indústria processadora de polpas instalada na cidade. Assim, foram apresentados pelos técnicos desta Indústria, dados que demonstravam que a cultura do maracujá oferecia viabilidade econômica e financeira caso fosse implantada essa lavoura nos lotes do assentamento.

Mesmo com o incentivo da doação das mudas e da assistência técnica, a cultura do maracujá como citada anteriormente não é de fácil cultivo, precisando assim de auxílios detalhados e atenção dobrada, ainda mais tratando de algo novo para os produtores que nunca haviam trabalhado no cultivo desta fruta.

A Tropical Poupa de Frutas Tangará Ltda foi fundada no ano de 2005, desde então realiza a fabricação de sucos concentrados de frutas, hortaliças e legumes. Tem em seu quadro de funcionários 16 colaboradores. A sua capacidade de produção total é de 180 toneladas/dia mas atualmente, por falta de matéria-prima a mesma esta com uma produção de 80 toneladas/dia aproximadamente 2 dias por semana. Seus principais clientes são a Nestlè (Rio de Janeiro), Tecnovin do Brasil (Rio Grande do Sul), Natura Suc (Rio Grande do Sul), Atlantica Foods (São Paulo), Coopernova (Mato Grosso), Brix Brasil (São Paulo), Natura Product (Rio Grande do Sul) e Wow Indústria e Comércio Ltda (São Paulo), como pode ser notado, apenas um dos 8 clientes é do Estado do Mato Grosso, segundo a própria industria a região não tem o tipo de comercio para o produto oferecido já que o mesmo é vendido apenas em grandes quantidades.

Pelo fato da falta de matéria-prima, a Indústria através de uma parceria, montou um projeto de incentivo para pequenos produtores, onde fornece as mudas, dá assistência técnica e auxilia os produtores no plantio, além de se comprometerem em adquirir toda a produção do maracujá a um valor de $\mathrm{R} \$ 0,60$ por quilo, em qualquer época do ano. A principio trata-se de uma opção viável de baixos custos e com lucratividade garantida pelos técnicos da indústria.

Os dados acima apresentados foram colhidos através da aplicação de questionário diretamente com o técnico responsável pela indústria. 


\subsection{Custos de implantação e produção na perspectiva da indústria processadora}

Tabela 1 - Gastos com Implantação

\begin{tabular}{|c|c|c|c|}
\hline 1.MATERIAIS E SERVIÇOS PARA ESTRUTURA & Quantidade & Valor Total & \\
\hline Moirões 3,0 m & 50 und & $\mathrm{R} \$$ & $2.750,00$ \\
\hline Estacas 2,5 m & 360 und & $\mathrm{R} \$$ & $3.456,00$ \\
\hline Arame Liso ${ }^{\circ} 12$ & 4 und & $\mathrm{R} \$$ & $1.200,00$ \\
\hline Kit Irrigação & 1 und & $\mathrm{R} \$$ & $4.200,00$ \\
\hline Barbantes & 3 rolos & $\mathrm{R} \$$ & 60,00 \\
\hline Abertura das covas & 20 dias & $\mathrm{R} \$$ & 600,00 \\
\hline INVESTIMENTO TOTAL & & $\mathbf{R} \$$ & $12.266,00$ \\
\hline
\end{tabular}

Fonte: Pesquisa de Campo Tangará da Serra-MT, 2011.

A indústria apresentou os dados acima como sendo o investimento que os produtores teriam para a implantação da cultura do maracujá em 1 há de terra, e para a plantação de 1000 mudas da fruta.

Tabela 2 - Custos de Manutenção Anuais

\begin{tabular}{lccrc}
\hline 2. CUSTOS DE MANUTENÇÃO & QUANTIDADE & \multicolumn{1}{c}{ VALOR TOTAL } & CUSTOS \\
\hline Mudas & 1.000 & $\mathrm{R} \$$ & 200,00 & variável \\
Calcário & $2 \mathrm{ton}$. & $\mathrm{R} \$$ & 100,00 & variável \\
Cama de aviário & 3 ton. & $\mathrm{R} \$$ & 300,00 & variável \\
MAP & $200 \mathrm{~kg}$ & $\mathrm{R} \$$ & 424,00 & variável \\
Sulfato de Amônia & $800 \mathrm{~kg}$ & $\mathrm{R} \$$ & $1.080,00$ & variável \\
Cloreto de Potássio & $450 \mathrm{~kg}$ & $\mathrm{R} \$$ & 900,00 & variável \\
Formicida & $2 \mathrm{~kg}$ & $\mathrm{R} \$$ & 20,00 & variável \\
Fungicida & $2 \mathrm{~kg}$ & $\mathrm{R} \$$ & 120,00 & variável \\
Inseticida & $2 \mathrm{lts}$ & $\mathrm{R} \$$ & 120,00 & variável \\
Adubos Foliar & $31 \mathrm{lts}$ & $\mathrm{R} \$$ & 60,00 & variável \\
Custos de energia & $2700 \mathrm{kWh}$ & $\mathrm{R} \$$ & 729,00 & fixo \\
\hline
\end{tabular}

Fonte: Pesquisa de Campo Tangará da Serra-MT, 2011.

Tabela 3 - Custos Com Serviços Anuais

\begin{tabular}{llcc}
\hline 2.1 SERVIÇOS & \multicolumn{2}{c}{ QUANTIDADE } & CUSTOS \\
\hline Preparo do solo & $\mathrm{R} \$$ & 360,00 & fixo \\
Espaldeiramento & $\mathrm{R} \$$ & 600,00 & fixo \\
Plantio e Adubação & $\mathrm{R} \$$ & 60,00 & fixo \\
Adubação de Cobertura & $\mathrm{R} \$$ & 60,00 & fixo \\
Irrigação & $\mathrm{R} \$$ & 300,00 & variável \\
Tratos Culturais & $\mathrm{R} \$$ & 900,00 & fixo \\
Controle Fitossanitário & $\mathrm{R} \$$ & 90,00 & fixo \\
Colheita, classificação e embalagem & $\mathrm{R} \$$ & $1.050,00$ & variável \\
Transporte para comercialização & $\mathrm{R} \$$ & $1.000,00$ & variável \\
\hline
\end{tabular}

TOTAL CUSTOS COM SERVIÇOS $\quad \mathbf{R} \$ \mathbf{4 . 4 2 0 , 0 0}$


Fonte: Pesquisa de Campo Tangará da Serra-MT, 2011.

Os dados apresentados acima mostram os custos apresentados pela industria que totalizam R \$ 8.473,00 sendo estes, $\mathrm{R} \$ 2.799,00$ Custos fixos (CF) e $\mathrm{R} \$$ 5.674,00 Custos Variáveis.

Tabela 4 - Cálculo da Receita

\begin{tabular}{lrr}
\hline RECEITA PREVISTA & \\
\hline Área Programada (hà) & 1 \\
Produtividade kg/há & $\mathrm{R} \$$ & 25.000 \\
Valor R\$ / kg & $\mathbf{R} \$ \mathbf{2 5 . 0 0 0 , 0 0}$ \\
\hline Receita Anual Prevista
\end{tabular}

Fonte: Pesquisa de Campo Tangará da Serra-MT, 2011.

Com base nos dados fornecidos pela indústria e evidenciados nas tabelas acima, o total de custos na implantação da cultura do maracujá é de $\mathrm{R} \$ 8.473,00$ para uma área de 1há plantadas, assim se o produtor vender toda a produção que no caso totaliza 25 toneladas, ele terá uma receita de $\mathrm{R} \$ 25.000$ bruto no primeiro ano. O prazo para a primeira colheita é de aproximadamente seis meses os primeiros frutos, mas o valor da receita com 25 toneladas é a projeção para 12 meses. Segue a demonstração de resultado do exercício com a apuração do lucro liquido:

\begin{tabular}{|l|cc|}
\hline \multicolumn{2}{|c|}{ DRE } \\
\hline Receita Bruta & $\mathrm{R} \$$ & $25.000,00$ \\
\hline (-) Custos Operacionais & $\mathrm{R} \$$ & $8.473,00$ \\
\hline (=)Lucro Operacional & $\mathrm{R} \$$ & $16.527,00$ \\
\hline (-) Despesas Financeiras & $\mathrm{R} \$$ & 800,00 \\
\hline (=)Lucro Líquido & $\mathrm{R} \$$ & $\mathbf{1 5 . 7 2 7 , 0 0}$ \\
\hline
\end{tabular}

Segundo dados apurados, o lucro líquido que é no valor de $\mathrm{R} \$ 14.927,00$ supriria o valor investido e ainda sobraria para o produtor o valor de $\mathrm{R} \$ 2.661,00$, o que pode ser colocado como um resultado positivo, pois já na primeira colheita ele quitaria a sua divida de investimento e como os pés de maracujá plantados são para duas colheitas, a do segundo ano seria ainda mais lucrativa já que fruticultor teria apenas os custos para manutenção da lavoura.

É importante ressaltar que o valor lançado como Despesas Financeira, corresponde a $2 \%$ de juros por ano, do valor financiado para a compra da terra.

Estes dados foram coletados diretamente do técnico responsável pela industria beneficiadora de poupa de frutas, onde o mesmo forneceu uma planilha com todas estas especificações.

\subsection{Custos de implantação e produção realizados pelos produtores rurais}


Tabela 5 - Gastos com a Implantação

\begin{tabular}{lcrr}
\hline 1. MATERIAIS E SERVIÇOS PARA ESTRUTURA & Quantidade & \multicolumn{2}{c}{ Valor Total } \\
\hline Moirões 3,0 m & 50 und & $\mathrm{R} \$$ & $2.750,00$ \\
Gradiação da Terra & 1 & $\mathrm{R} \$$ & 320,00 \\
Estacas $2,5 \mathrm{~m}^{\text {Arame Liso n }}{ }^{\mathbf{0}} 12$ & 360 und & $\mathrm{R} \$$ & $3.456,00$ \\
Caixa d`gua & 4 und & $\mathrm{R} \$$ & $1.200,00$ \\
Bomba & 1 und & $\mathrm{R} \$$ & $3.500,00$ \\
Mangueira & 1 und & $\mathrm{R} \$$ & $1.200,00$ \\
Canos & $3500 \mathrm{~m}$ & $\mathrm{R} \$$ & $1.400,00$ \\
Construção do pé da caixa d'gua & 22 barras & $\mathrm{R} \$$ & 440,00 \\
Catracas & 1 & $\mathrm{R} \$$ & 810,00 \\
Poço Artesiano & 22 & $\mathrm{R} \$$ & 374,00 \\
Abertura de Covas & 1 & $\mathrm{R} \$$ & 245,84 \\
\hline INVESTIMENTO TOTAL & 20 dias & $\mathrm{R} \$$ & 600,00 \\
\hline
\end{tabular}

Fonte: Dados da pesquisa, 2011.

Tabela 6 - Custos de Manutenção

\begin{tabular}{lcccc}
\hline 2. CUSTOS DE MANUTENÇÃO & QUANTIDADE & VALOR TOTAL & CUSTOS \\
\hline Mudas & 1.000 & $\mathrm{R} \$$ & 200,00 & variável \\
Calcário & 2 ton. & $\mathrm{R} \$$ & 100,00 & variável \\
Cama de aviário & 3 ton. & $\mathrm{R} \$$ & 360,00 & variável \\
MAP & $200 \mathrm{~kg}$ & $\mathrm{R} \$$ & 424,00 & variável \\
Sulfato de Amônia & $720 \mathrm{Kg}$ & $\mathrm{R} \$$ & $1.080,00$ & variável \\
Cloreto de Potássio & $450 \mathrm{~kg}$ & $\mathrm{R} \$$ & 900,00 & variável \\
Formicida & $2 \mathrm{~kg}$ & $\mathrm{R} \$$ & 20,00 & variável \\
Fungicida & $3 \mathrm{~kg}$ & $\mathrm{R} \$$ & 180,00 & variável \\
Inseticida & $4 \mathrm{lts}$ & $\mathrm{R} \$$ & 240,00 & variável \\
Adubos Foliar & $120 \mathrm{~kg}$ & $\mathrm{R} \$$ & 168,00 & variável \\
Fosfato & $120 \mathrm{~kg}$ & $\mathrm{R} \$$ & 180,00 & variável \\
Uréia & $110 \mathrm{~kg}$ & $\mathrm{R} \$$ & 187,00 & variável \\
Custos de energia & $101 \mathrm{kwh}$ & $\mathrm{R} \$$ & 27,00 & fixo \\
\hline \multicolumn{2}{c}{} & & &
\end{tabular}

Fonte: Dados da Pesquisa, 2011.

Tabela 7 - Custos com Serviços

\begin{tabular}{llrl}
\hline 2.1 SERVIÇOS & \multicolumn{2}{l}{ VALOR TOTAL } & CUSTOS \\
\hline Irrigação & $\mathrm{R} \$$ & 300,00 & variável \\
Controle Fitossanitário & $\mathrm{R} \$$ & 90,00 & fixo \\
Transporte para comercialização & $\mathrm{R} \$$ & $1.000,00$ & variável \\
Mão-de-Obra & $\mathrm{R} \$$ & $4.800,00$ & fixo \\
Frete do calcário & $\mathrm{R} \$$ & 132,00 & variável \\
Serviço para espalhar o Calcário & $\mathrm{R} \$$ & 165,00 & variável \\
Gradiação da Terra & $\mathrm{R} \$$ & 320,00 & variável \\
\hline
\end{tabular}

Fonte: Dados da Pesquisa, 2011.

Estes dados foram coletados através do acesso a notas fiscais diretamente coletadas com os produtores, os mesmos tinham todos os documentos fiscais arquivados.

\begin{tabular}{|l|lr|}
\hline Total dos Custos (manutenção+serviços) & R\$ & $10.873,00$ \\
\hline
\end{tabular}


Através da apuração feita diretamente de dados coletados dos produtores chegou-se a um custo total de manutenção da lavoura de $\mathrm{R} \$ 10.873,00$ sendo destes $\mathrm{R} \$ 4.917,00$ Custos Fixos (CF), e R\$ 5.956,00 de Custos Variáveis (CV).

Pelo fato dos pequenos produtores serem pessoas leigas, os mesmos não tinham conhecimento de qual a diferença entre custos fixos e custos variáveis. Após a coleta dos valores foram feitas as classificações seguindo os conceitos apresentados pelos autores citados.

Tabela 8 - Cálculo da Receita Total Comercializada com Industria (dados do produtor)s

\begin{tabular}{lrr}
\hline RECEITA EFETIVA & \\
\hline Área Programada (hà) & 1 \\
Produtividade ton./há & 3000 \\
Valor R\$ / Kg & R\$ & 0,60 \\
\hline Receita Anual Efetiva & $\mathbf{R} \$$ & $\mathbf{1 . 8 0 0 , 0 0}$ \\
\hline
\end{tabular}

Fonte: Dados da Pesquisa, 2011.

Tabela 9 - Cálculo da receita comercializado com terceiros(dados do produtor)

\begin{tabular}{lrr}
\hline RECEITA EFETIVA & \\
\hline Área Programada (hà) & & 1 \\
Produtividade ton./há & $\mathrm{R} \$$ & 1200 \\
Valor R\$ / Kg & $\mathbf{R} \$$ & $\mathbf{1 . 8 0 0 , 0 0}$ \\
\hline Receita Anual Efetiva
\end{tabular}

Fonte: Dados da Pesquisa, 2011.

Pelos dados coletados diretamente do produtor através de notas fiscais da parte que eles comercializaram com a Indústria e de relato sobre o valor comercializado com terceiro, pode ser percebido primeiramente que o valor de quilos que a indústria colocou como o esperado não foi alcançado, sendo um valor bem menor do que apresentado no projeto, isso se deu pelo fato de uma praga que afetou diretamente o solo. Os produtores justificam a perda de grande parte da colheita por falta de assistência técnica, já que a cultura do maracujá não é de fácil cultivo e necessita de acompanhamento rigoroso. Segue a demonstração do resultado do exercício onde mostra o Prejuízo referente ao primeiro ano de colheita.

\begin{tabular}{|c|cc|}
\hline \multicolumn{2}{|c|}{ DRE } \\
\hline Receita Bruta & $\mathrm{R} \$$ & $3.600,00$ \\
\hline (-) Custos Operacionais & $\mathrm{R} \$$ & $10.873,00$ \\
\hline (=)Lucro Operacional & $\mathrm{R} \$$ & $(7.273,00)$ \\
\hline (-) Despesas Financeiras & $\mathrm{R} \$$ & 800,00 \\
\hline (=)Prejuízo & $\mathbf{R} \$$ & $\mathbf{( 8 . 0 7 3 , 0 0})$ \\
\hline
\end{tabular}


Através da apuração do resultado do exercício pode ser percebido que os produtores não conseguiram nem suprir os seus custos de manutenção do cultivo do maracujá, logo não tiveram lucro para pagamento do investimento. Além dos custos e despesas apresentados, os produtores pagam anualmente aproximadamente $\mathrm{R} \$ 2.500,00$ de parcela do financiamento da terra, assim a situação fica mais complicada pois sem lucratividade a situação financeira dos fruticultores se torna mais complicada. É relevante ressaltar que os custos com mudas foram colocados nas tabelas apenas para demonstração, mas estes valores não estão incluídos no cálculo já que as mesmas são fornecidas pela Indústria.

Foram realizados cálculos de indicadores financeiros para melhor demonstrar a verdadeira situação dos produtores.

\section{Lucratividade Anual}

$$
\begin{aligned}
& \text { Lucratividade }=\frac{\text { Lucro Líquido }}{\text { Receita Total }} \times 100 \\
& \text { Lucratividade }=\frac{-\mathrm{R} \$}{\mathrm{R} \$} \frac{8.873,00}{3.600,00} \times 100
\end{aligned}
$$

O índice de lucratividade pode mensurar o ganho em valores presentes, como na apuração de resultados chegou-se a um resultado negativo os produtores tiveram um prejuízo de $\mathrm{R} \$ 246,47$ a cada $\mathrm{R} \$ 100,00$ comercializado da fruta nesta primeira colheita.

\section{Rentabilidade Anual}

$$
\begin{aligned}
& \text { Rentabilidade }=\frac{\text { Lucro Líquido }}{\text { Investimento Total }} \times 100 \\
& \text { Rentabilidade }=\frac{-\mathrm{R} \$}{\mathrm{R} \$} \quad \frac{8.873,00}{16.295,84} \times 100
\end{aligned}
$$


Neste caso o indicador permite conhecer se houve rentabilidade do investimento porém o produtor teve $\mathrm{R} \$ 54,44$ de prejuízo para cada $\mathrm{R} \$ 100,00$ investidos na implantação da cultura do maracujá, logo não teve nenhum retorno do valor que ele investiu no primeiro ano de colheita.

É interessante apresentar o tempo decorrido entre o investimento inicial e o momento no qual o lucro líquido acumulado se iguala ao valor desse investimento. Não foi possível essa demonstração, pois os produtores não obtiveram lucro, sendo impossível assim fazer este cálculo.

\section{CONCLUSÃO}

Após um levantamento dos custos feito diretamente dos produtores confrontados com dados fornecidos pela Indústria, pode ficar claro que a cultura do maracujá neste caso, não foi lucrativa nem rentável para os pequenos produtores já que os mesmo tiveram prejuízo, não sendo possível nem cobrir os gastos com a implantação do projeto.

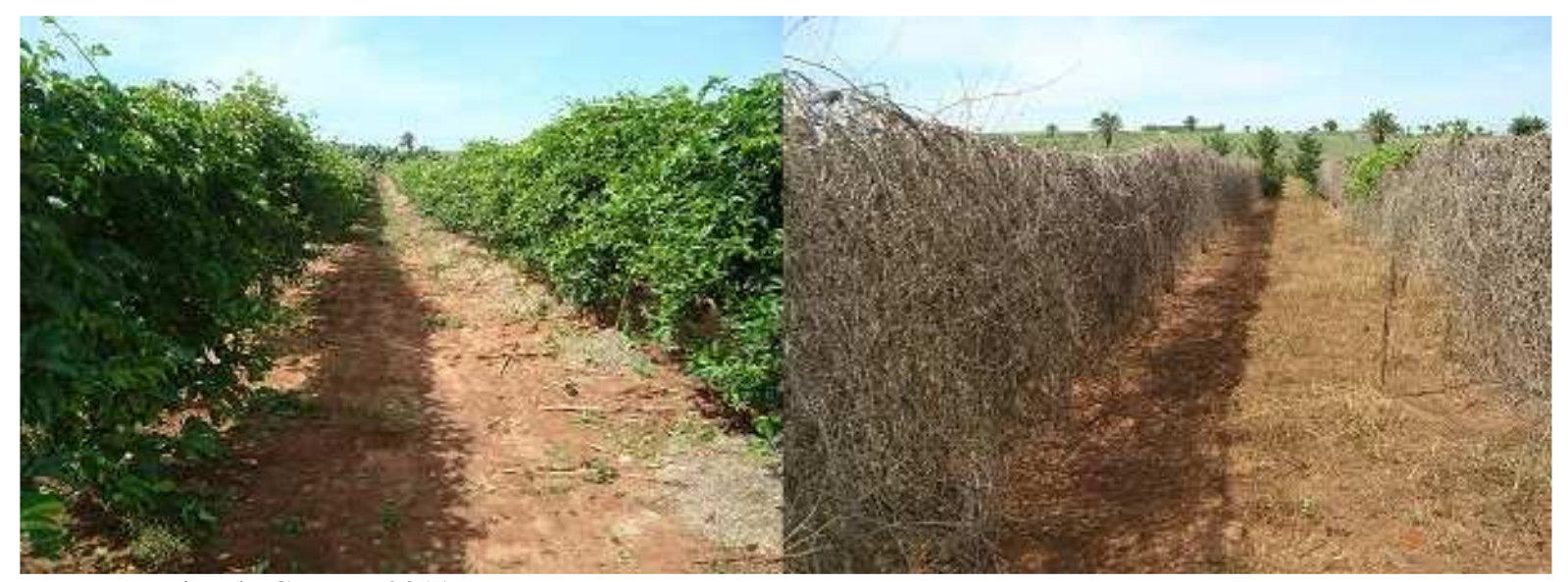

Foto: Pesquisa de Campo, 2011.

Para os produtores a perda de grande parte da colheita, se deu ao fato de uma praga que afetou a terra, isso pela falta de assistência técnica já que estes não dominavam os conhecimentos sobre a cultura do maracujá. Mesmo sendo visível que estes não estavam tendo lucratividade, foi de grande surpresa os valores apresentados já que não se pode nem mensurar em quanto tempo eles terão o retorno do valor investido. O impacto não se dá apenas economicamente na vida dos produtores, mas também socialmente, já que eles se sentem impotentes por não estarem cumprindo suas obrigações financeiras com o plantio do maracujá. 
A questão levantada no problema foi respondida e a hipótese aceita foi a de que não há vantagens para os pequenos produtores do assentamento Vale do Sol II quanto ao cultivo do maracujá, mesmo com o incentivo dado pela Indústria. Essa falta de sucesso pode ser justificada pelo fato da falta de assistência técnica, falta do uso de tecnologia e por uma praga que afetou a terra e comprometeu boa parte do plantio.

\section{REFERÊNCIAS BIBLIOGRÁFICAS}

BEZZON, Lara Crivelaro. Guia Prático de Monografia, dissertações e tese: Elaboração e apresentação. 3. Ed. Campinas - SP: Alinea, 2005.

BOTH, Sergio José. SIQUEIRA, Claudineide Julião de Souza. Metodologia Cientifica: faça fácil sua pesquisa. Tangará da Serra - MT: São Francisco, 2004.

Embrapa;http://www.embrapa.br/imprensa/artigos/2002/artigo.2004-12-07.2590963189/ acesso em 10 de Maio de 2011.

http://www.noticiasagricolas.com.br/noticias/hortifruti/76692-fruticultura-procura-caminhopara-se-consolidar.html;Fruticultura procura caminho para consolidar ; acesso em 12 de Setembro de 2011.

http://www.agrosoft.org.br/agropag/25568.htm; Produtores de Tangará da Serra (MT) investem na produção do abacaxi e maracujá; acesso em 12 de Setembro de 2011.

INSTITUTO CENTRO DE ENSINO (CENTEC). Produtor de Maracujá. 1. Ed. Fortaleza: Demócrito Rocha, 2004.

MARTINS, Eliseu. Contabilidade de Custos. 9.Ed. - São Paulo: Atlas, 2003.

MEGLIORINI. Evanir. Custos, análise e gestão. 2. Ed. São Paulo: Pearson Prentice Hall, 2006.

Ministério do Desenvolvimento Agrário;http://www.mda.gov.br/portal/saf/;acesso em 01 de Setembro de 2011.

NELMAN, Pedro Selvino. Desenvolvimento Rural: tendências e debates contemporâneos. 2. Ed. - Ijuí: Unijuí, 2009.

PEREZ JR., José Hernandes; OLIVEIRA, Luís Martins de; COSTA, Rogério Guedes. Gestão estratégica de custos. 2 ed. São Paulo: Editora Atlas S.A., 2008.

PORTUGUAL, Duque Alberto. O desafio da Agricultura familiar. 2004. Disponível em www.embrapa.br/imprensa/artigos/2002/artigo.2004-12-07.2590963189/ Acesso em 30 de Setembro de 2011.

SEVERINO, Antonio Joaquim. Metodologia do trabalho cientifico. 22 Ed. - São Paulo: Cortez, 2002. 